\title{
Establecimiento de un banco de proteína, pasto de corte y lombricultivo en un sistema familiar de producción ovina
}

\section{Establishment of a protein bank, grass cutting and vermiculture in a familiar system of sheep production}

\author{
Bernal Moncada Carlos Mario ${ }^{1}$, Jaramillo Dumar Alexander ${ }^{2}$ y \\ Hernández Juan Pablo ${ }^{3}$ \\ ${ }^{1} \mathrm{MVZ}$, Unillanos, ${ }^{2} \mathrm{MVZ}$, Esp., (c)MSc. Líder Grupo de Investigación en \\ Farmacología Experimental y Medicina Interna - Élite, Profesor Clínica de \\ Grandes Animales, Universidad de los Llanos y \\ ${ }^{3}$ Admon Emp., Jefe Fundación MIMA \\ carlos.bernal@unillanos.eu.co
}

Recibido 12 de Diciembre 2014, Aceptado 26 de Septiembre 2015

\section{RESUMEN}

Este proyecto agropecuario fue desarrollado con la Fundación MIMA en coordinación con UNILLANOS, en la granja Niquia ubicada en la vereda Indostán, km 39 vía Puerto López, en el municipio de Villavicencio-Meta. El análisis edafológico determina que el suelo de la finca es de baja calidad, por lo tanto, requieren ser mejorados mediante prácticas de agricultura sostenible, fertilizando con abonos orgánicos y mejorando su estructura física con las lombrices de tierra. El trabajo tuvo por objetivo establecer bancos de proteína de Tithonia diversifolia y Moringa oleifera, pasto de corte (Pennisetum purpureum var. Panamá común) y lombricultivo (Eisenia foetida) en un sistema de producción ovino. Se utilizaron 705 estacas de Tithonia diversifolia con $30 \mathrm{~cm}$ de largo y 2.5 a $3.5 \mathrm{~cm}$ de grosor, que fueron sembradas en bolsa de polietileno con capacidad para $1 \mathrm{~kg}$, la cual se llenó $3 / 4$ de tierra y $1 / 4$ de humus sólido, para luego trasplantarla al sitio definitivo; para el banco de proteína se utilizó un área total de $240 \mathrm{~m}^{2}$. Las semillas de moringa se sembraron en vivero de manera similar al botón de oro. En total se sembraron 1121 plantas en un área de $1440 \mathrm{~m}^{2}$ distribuidos en dos lotes, y se utilizaron 15.5 bultos $(40 \mathrm{~kg} \mathrm{c} / \mathrm{u})$ de humus sólido cuando se trasplantaron al sitio definitivo. La producción de materia fresca en el primer y segundo lote fue: 250 y $190 \mathrm{~g} /$ planta 
respectivamente. El área de siembra de Pennisetum purpureum var. Panamá fue $1060 \mathrm{~m}^{2}$, y la totalidad cosechada fue aproximadamente 4,5 toneladas, con una producción de $4 \mathrm{~kg} / \mathrm{m}^{2}$. El lombricultivo ha mostrado ser una estrategia clave en el desarrollo del proyecto, puesto que se usa el humus para fertilizar los cultivos, además la venta externa genera un ingreso monetario adicional, por lo tanto, esta tecnología contribuye a solucionar dos de los problemas ambientales que se deben enfrentar en la actualidad: la acumulación de grandes concentraciones de residuos orgánicos en las fincas y la necesidad de materia orgánica en los suelos agrícolas.

Palabras clave: Ovinos, Moringa oleifera, Tithonia diversifolia, Eisenia foetida, abono orgánico.

\section{ABSTRACT}

This farming project was developed with the MIMA Foundation, in coordination with UNILLANOS, on Niquia farm located in the village of Indostán, $39 \mathrm{~km}$ way Puerto López, in the municipality of Villavicencio-Meta. The soil analysis determines that farm soil is low quality, therefore, needs to be improved through sustainable agricultural practices, fertilization with organic fertilizers and improving its physical structure with earthworms. The study aimed to establish food plots of Tithonia diversifolia and Moringa oleifera, grass cutting (Pennisetum purpureum var. Panamá) and vermiculture in a system of sheep production. 705 stakes were used of Tithonia diversifolia with $30 \mathrm{~cm}$ long and 2.5 to $3.5 \mathrm{~cm}$ thick, which were planted in polyethylene bags with a capacity of $1 \mathrm{~kg}$, which is filled $3 / 4$ of earth and $1 / 4$ of solid humus, and then transplant it to the definitive site; for protein bank a total area of $240 \mathrm{~m}^{2}$ was used. Moringa seeds were sown in nursery similar manner to the Tithonia diversifolia. In total 1121 plants were sown in an area of $1440 \mathrm{~m}^{2}$, distributed in two lots and 15.5 packages $(40 \mathrm{~kg} \mathrm{c} / \mathrm{u})$ of solid humus were used when they transplanted to the definitive site. The production of fresh material on the first and second batch was 250 and $190 \mathrm{~g} /$ plant respectively. The planting area of Pennisetum purpureum var. Panamá was $1060 \mathrm{~m}^{2}$, and all harvested was about 4.5 tons, with a production of $4 \mathrm{~kg} / \mathrm{m}^{2}$. The vermiculture has proven to be a key 
strategy in developing the project, because the humus is used to fertilize crops, furthermore the external sale generates additional cash income, therefore, this technology contributes to solve two of the environmental problems they face today: the accumulation of high concentrations of organic waste on farms and the need of organic matter in agricultural soils.

Keywords: Sheep, Moringa oleifera, Tithonia diversifolia, Eisenia foetida, organic fertilizer.

\section{RESUMO}

Este projecto agrícola foi desenvolvido com a Fundação MIMA, em coordenação com UNILLANOS, na fazenda Niquia localizado na vila de Indostan, $39 \mathrm{~km}$ via Puerto López, no município de Villavicencio-Meta. O análise do solo determina que solo agrícola é de baixa qualidade, portanto, exigem melhoria por meio de práticas agrícolas sustentáveis, adubação com adubos orgánicos e melhorando sua estrutura física com minhocas. O estudo teve como objetivo estabelecer bancos de proteína de Tithonia diversifolia e Moringa oleifera, corte de grama (Pennisetum purpureum var. Panamá) e vermiculture (Eisenia foetida) em um sistema de produção de ovinos. Foram utilizados 705 estacas de Tithonia diversifolia com $30 \mathrm{~cm}$ de comprimento e 2.5 a $3.5 \mathrm{~cm}$ de espessura, que foram plantadas em sacolas de polietileno com capacidade de $1 \mathrm{~kg}$, que foi enchido $3 / 4$ de terra e 1/4 de húmus sólidoe depois transplantadas para o local definitivo; para o banco de proteína foi usado uma área total de $240 \mathrm{~m}^{2}$. Sementes de moringa foram semeadas em viveiro da mesma forma a Tithonia diversifolia. No total, 1121 plantas foram semeadas numa área de $1440 \mathrm{~m}^{2}$, divididas em dois lotes e foram utilizados 15.5 embalagens ( $40 \mathrm{~kg} \mathrm{c} / \mathrm{u}$ ) de húmus sólido quando transplantado se para o local final. O produção de material fresco no primeiro e segundo lote foi de 250 e $190 \mathrm{~g} /$ planta, respectivamente. A área de plantação de Pennisetum purpureum var. Panamá foi $1060 \mathrm{~m}^{2}$, e tudo recolhido foi cerca de 4.5 toneladas, com uma produção de $4 \mathrm{~kg} / \mathrm{m}^{2}$. O vermiculture provou ser uma estratégia-chave no desenvolvimento do projeto, sendo que o húmus é usado para fertilizar plantas, além disso a venda externa gera entrada adicional em dinheiro, portanto, esta 
tecnologia contribui para resolver dois dos problemas ambientais que deben se afrontar na actualidade: o acúmulo de altas concentrações de resíduos orgânicos em fazendas e necessidade de matéria orgânica em solos agrícolas.

Palavras-chave: Ovelha, Moringa oleifera, Tithonia diversifolia, Eisenia foetida, adubo orgánico.

\section{INTRODUCCIÓN}

En el último siglo, la agricultura moderna intensiva (monocultivos), ha utilizado indiscriminadamente insumos como plaguicidas, herbicidas y fertilizantes sintéticos, lo cual ha tenido un impacto nocivo sobre la diversidad de los recursos genéticos vegetales y animales (domésticos), y flora y fauna (silvestres) (FAO, 1999), puesto que los campos arables constituyen el hábitat para una amplia gama de especies que están en peligro debido a la intensificación agrícola que ha destruido los ecosistemas naturales (FAO, 2003).

La creación de proyectos agropecuarios enfocados para obtener productos mediante un manejo responsable y sostenible, se puede considerar importante para la recuperación de suelos, donde se ha trabajado agricultura intensiva, también se ha comprobado que el uso de lombriz de tierra que recicla nutrientes del suelo y es fuente de abono orgánico, puede mejorar las condiciones de este recurso. Por otra parte los bancos de proteína para la alimentación de animales, y huertas comunitarias, son actividades que pueden ser empleadas con el fin de optimizar las condiciones ambientales para el bienestar de las especies domésticas y silvestres (Pérez y Rojas, 2008).

Por lo tanto el objetivo de este trabajo fue implementar un banco de proteína con base en las especies Moringa oleífera y Tithonia diversifolia como alternativa de alimentación en sistemas de producción ovino de la vereda Indostán. También se evaluó el comportamiento productivo del pasto de corte Pennisetum purpureum var. Panamá común, como soporte de alimentación en sistemas de producción mencionados. Además se estableció el lombricultivo como método de reducción 
del impacto ambiental en la disposición de los residuos orgánicos sólidos producidos en los sistemas de producción animal.

\section{UBICACIÓN Y DISTRIBUCIÓN DE LA GRANJA}

El proyecto se realizó con la Fundación MIMA en coordinación con UNILLANOS, en la granja Niquia, que tiene como economía familiar la producción de ovinos, la cual se encuentra ubicada en el kilómetro 39 vía Villavicencio - Puerto López, a dos $\mathrm{km}$ de la vereda Indostán por la vía que conduce a Puerto Porfía. El departamento del Meta tiene un clima cálido húmedo a semihúmedo, la precipitación para el año 2014 fue de $2999.91 \mathrm{~mm}$, con una temperatura promedio de $26^{\circ} \mathrm{C}$ y a una altitud de $225 \mathrm{msnm}$ (IDEAM, 2014).

La granja cuenta con áreas de siembra de botón de oro (Tithonia diversifolia), moringa (Moringa oleifera), pasto de corte King grass (Pennisetum purpureum var. panamá común) y potreros con Brachiaria spp, además se cultiva: plátano, yuca y una huerta con algunas hortalizas, también se cuenta con seis camas de lombrices californianas (Eisenia foetida) de $1.50 \mathrm{~m}$ de ancho por $5 \mathrm{~m}$ de largo y 40 $\mathrm{cm}$ de alto. Dentro de su infraestructura la finca tiene casa y aprisco (Figura 1)

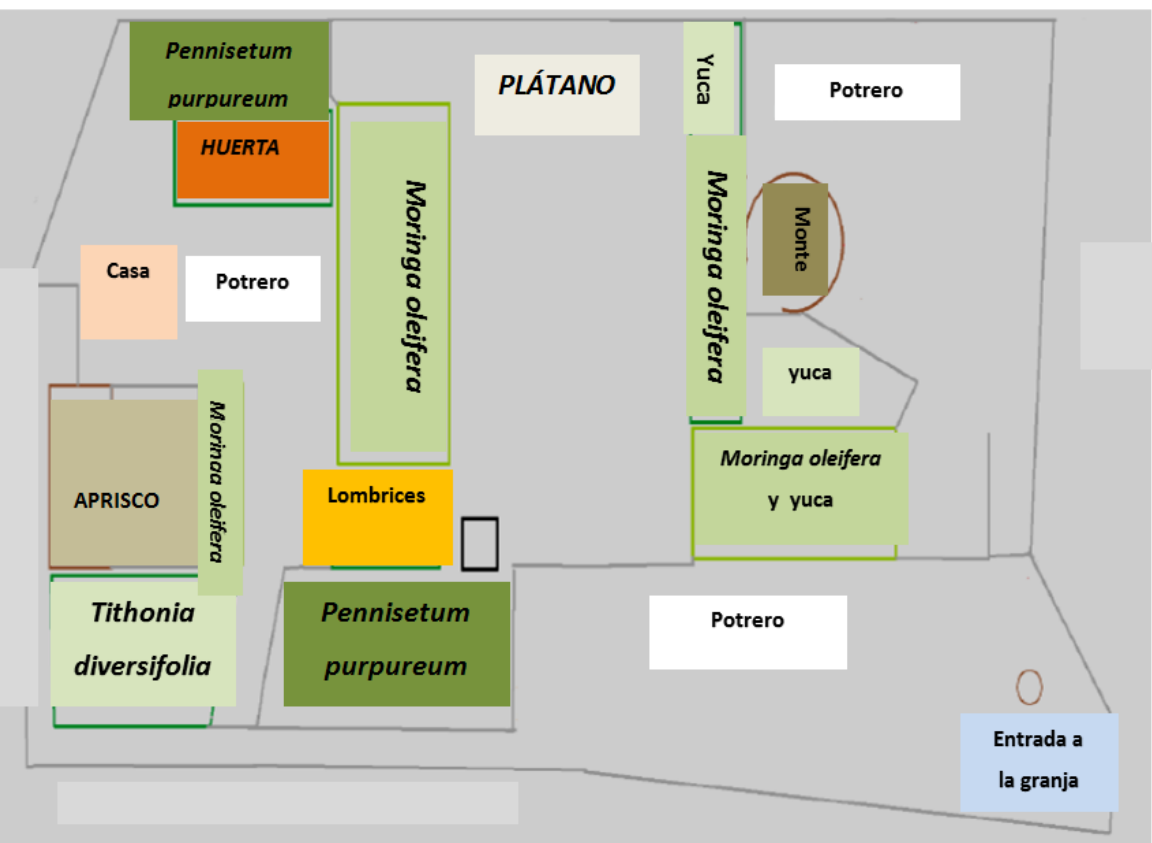

Figura 1. Distribución de la granja Niquia. Fuente: Los autores 
El análisis edafológico determina que es el suelo de la finca es de textura francoarenosa, tiene $\mathrm{pH}$ extremadamente acido (4.0), materia orgánica deficiente $(0.9 \%)$; con poca capacidad de retención de agua, elevada permeabilidad, buen drenaje y aireación. Desde el punto de vista químico son bajos en: fósforo, zinc y boro 1.5, $0.42,0.14 \mathrm{mg} / \mathrm{kg}$, además en calcio, potasio, magnesio y sodio $1.42,0.06,0.07$, $0.08 \mathrm{cmol} / \mathrm{kg}$ respectivamente, de acuerdo a estos resultados se consideran suelos de baja calidad, por lo tanto, requieren ser mejorados mediante prácticas de agricultura sostenible, fertilizando con abonos orgánicos y mejorando su estructura física con las lombrices de tierra.

\section{BANCO DE PROTEÍNA CON Tithonia diversifolia}

Tithonia diversifolia es conocida como "botón de oro", es una planta herbácea o arbustiva robusta, perteneciente, originaria de México y Centro América desde donde se ha distribuido a diversas partes del mundo dentro de ellas Colombia, donde crece en condiciones agroclimáticas variadas, desde el nivel del mar hasta los 2700 metros de altitud, con precipitaciones anuales entre 800 a $5000 \mathrm{~mm}$ y en diferentes tipos de suelo, además tolera condiciones de acidez, de baja fertilidad y crece espontáneamente en áreas perturbadas a orillas de caminos, ríos y carreteras (González et al., 2014). La planta restablece rápidamente la fertilidad y los nutrientes de los suelos degradados (Inayat y Gordon, 2009). La biomasa producida por Tithonia diversifolia varía entre 30 y 70 ton/ha de forraje verde dependiendo de la densidad de siembra, el tipo de suelo, el estado vegetativo y las condiciones ambientales (Medina et al., 2009). El uso de Tithonia diversifolia para la alimentación animal es cada vez más generalizado debido a su alta rusticidad, buen valor nutricional, alta digestibilidad de la materia seca y la presencia de aceites en sus hojas y flores; además, de la elevada tasa de producción de biomasa, alcanzando anualmente las 77 toneladas de carbono por hectárea (Mahecha et al., 2007).

Se utilizaron 705 estacas de Tithonia diversifolia con $30 \mathrm{~cm}$ de largo y 2.5 a $3.5 \mathrm{~cm}$ de grosor, éstas fueron sembradas en bolsa de polietileno con capacidad para 1 $\mathrm{kg}$, la cual se llenaba $3 / 4$ de tierra y $1 / 4$ de humus sólido, para luego trasplantarla 
al sitio definitivo. Para conformar el banco de proteína de esta especie se utilizó un área $174 \mathrm{~m}^{2}$ y luego se sembró otra área de $66 \mathrm{~m}^{2}$, para un total de $240 \mathrm{~m}^{2}$ (Figura 2).

En la primera área (bloque 1) fueron sembradas 175 plantas de Tithonia diversifolia en 9 surcos como lo ilustra y 530 plantas en la segunda área (bloque 2) en 26 surcos para un total de 705 plantas (Figura 3). En el bloque 1 no se utilizó humus, mientras que en el bloque 2 las estacas fueron sembrados con $2 \mathrm{~kg}$ de humus sólido, $1 \mathrm{~kg}$ en el hueco y $1 \mathrm{~kg}$ por fuera. Dentro de los bloques las plantas se situaron teniendo en cuenta las siguientes dimensiones para la siembra: $50 \mathrm{~cm}$ entre plantas, $70 \mathrm{~cm}$ entre surco, y $1 \mathrm{~m}$ cada 4 surcos (Figura 3 ).

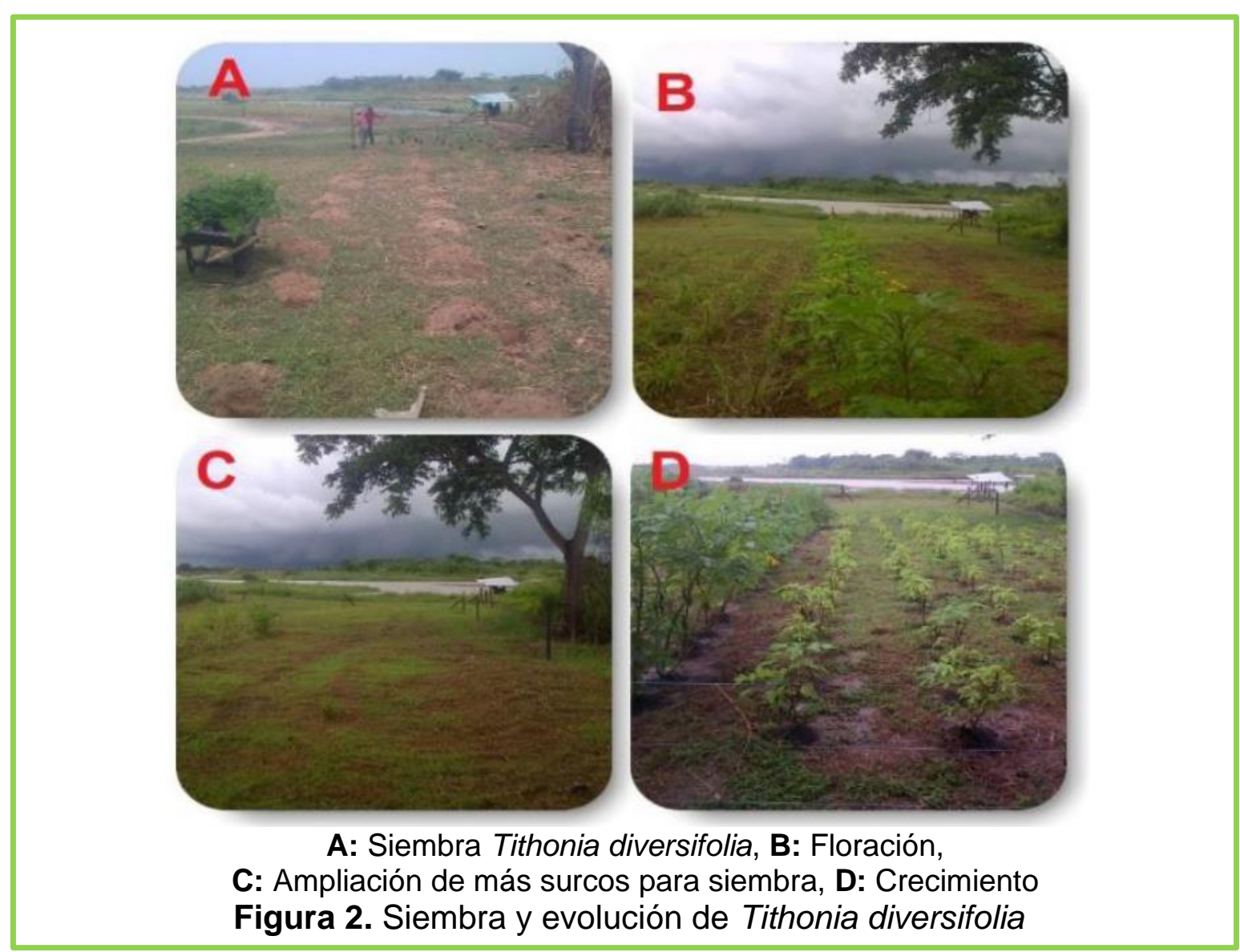

\section{Cosecha de Tithonia diversifolia}

A los 55 días se realizó una poda de nivelación, luego, se realizaron tres cortes cada 67 y 47 días para el bloque uno y dos respectivamente, siendo la producción 
total de forraje verde (FV) para el bloque uno de $35,5 \mathrm{~kg}$ y para el dos de $212 \mathrm{~kg}$ con promedio de: 3.2 y $3.85 \mathrm{~kg} / \mathrm{corte}$, respectivamente, estás evaluaciones se realizaron durante un 256 días. Con la aplicación del humus sólido se observó una reducción de más de dos semanas en los días de corte, y un aumento de $300 \mathrm{gr}$ de materia fresca en el mismo periodo. La cosecha se hizo en prefloración, la cual se realizó por surco completo, posteriormente, se abonó la planta con $500 \mathrm{~g}$ de humus sólido en la base de la misma. (Figuras 4 y 5 ).

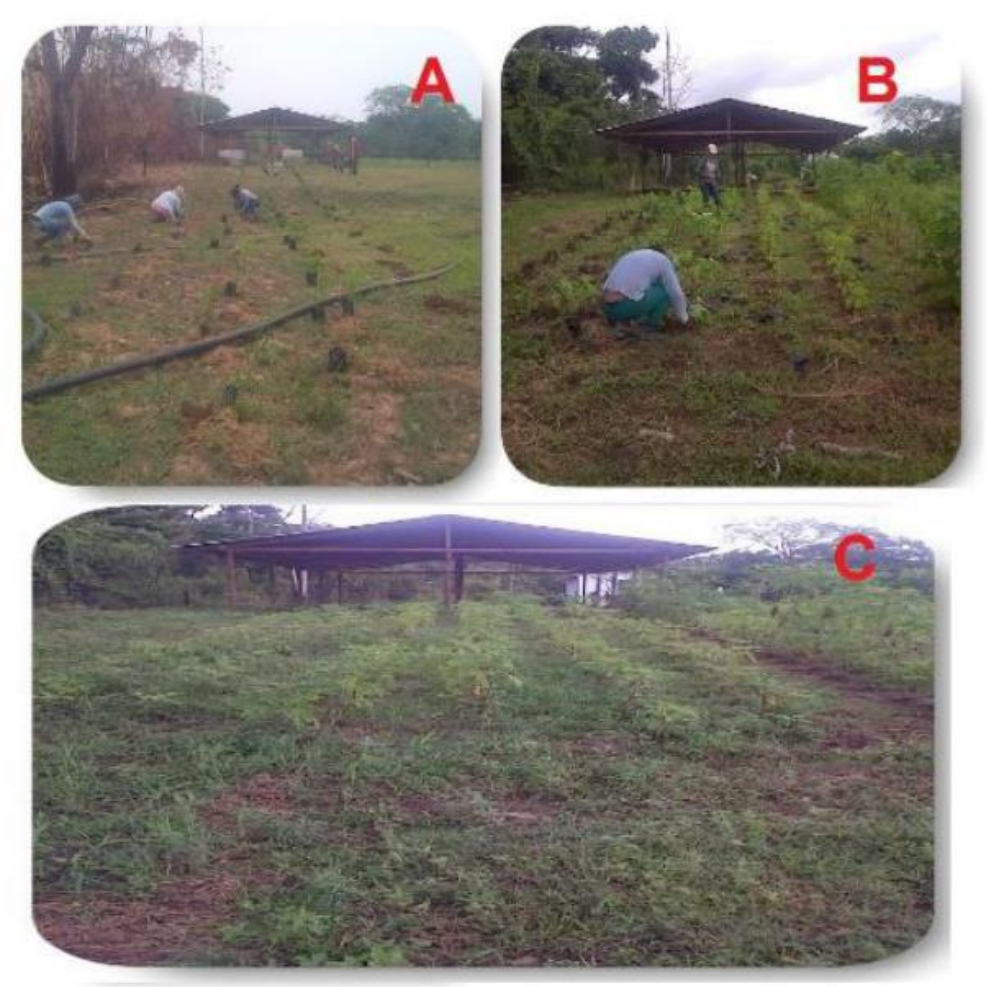

A: Siembra Tithonia diversifolia, B: Siembra en surcos, C: Vista occidente - oriente del primer bloque de Tithonia diversifolia.

Figura 3. Primer bloque del banco de proteína con Tithonia diversifolia

De cada cosecha ofrecida a los animales las ramas que tenían un grosor entre 1.5 y $2 \mathrm{~cm}$ se seleccionaron para la siembra en bolsas de polietileno de $1 \mathrm{~kg}$ siendo llenadas en un cuarto de su capacidad con humus sólido, esta práctica fue realizada debido a la experiencia positiva, que se tenía con el uso de este abono. Se presentaron muy pocos problemas fitosanitarios, entre los que se encuentra algunas hojas masticadas por gusanos, y cambios de coloración en la hoja por encharcamientos prolongados (Figuras 6 y 7 ). 

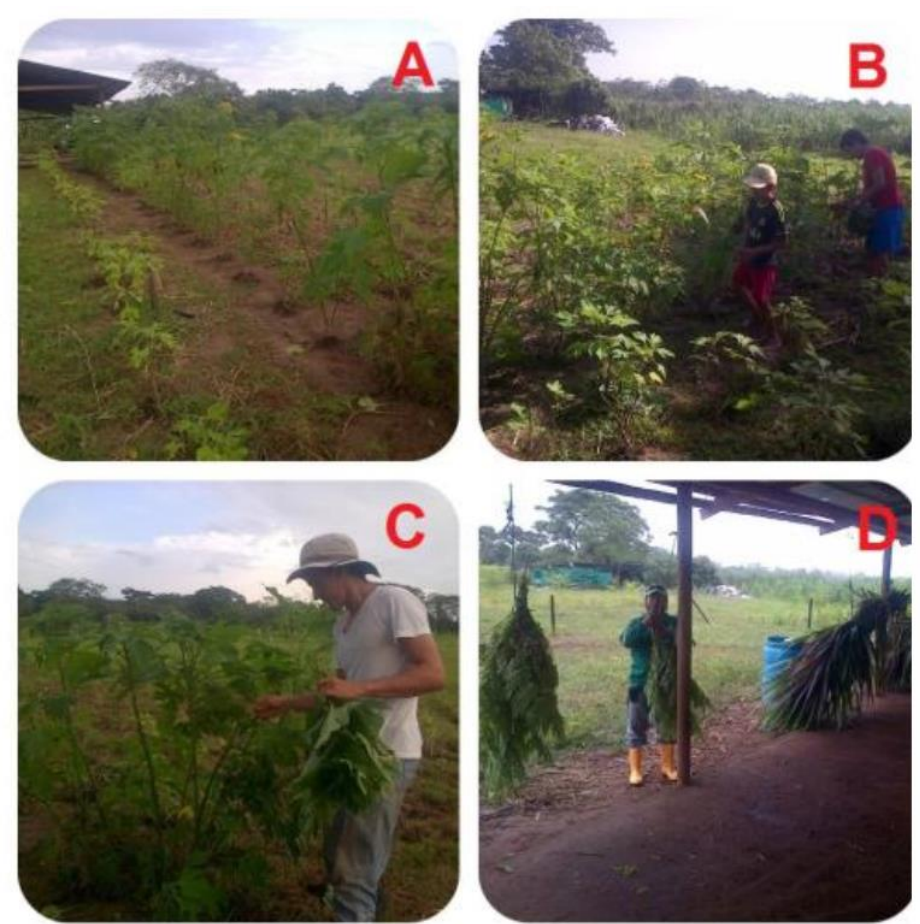

A: Surco uno, abonado con humus sólido y limpieza entre surcos, B: Hijos de beneficiarios del proyecto cosechado Tithonia diversifolia, C: Cosecha del bloque dos,

D: Mezcla de forraje fresco de Tithonia diversifolia y Moringa oleifera.

Figura 4. Diferentes etapas en la cosecha de Tithonia diversifolia

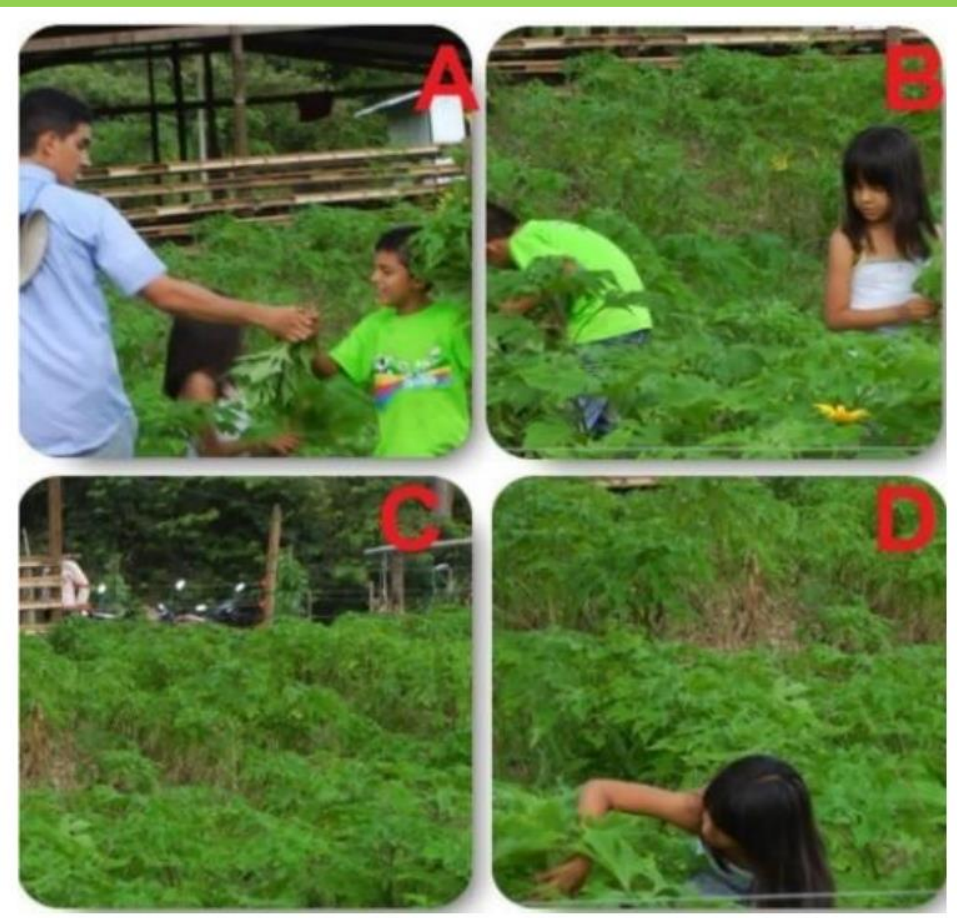

A: hijos de beneficiarios en cosecha de Tithonia diversifolia,

B: aprehensión de las prácticas de cosecha, C: Vista bloque dos, D: cosecha bloque dos de Tithonia diversifolia

Figura 5. Cosecha y explicación a hijos de beneficiarios del proyecto 


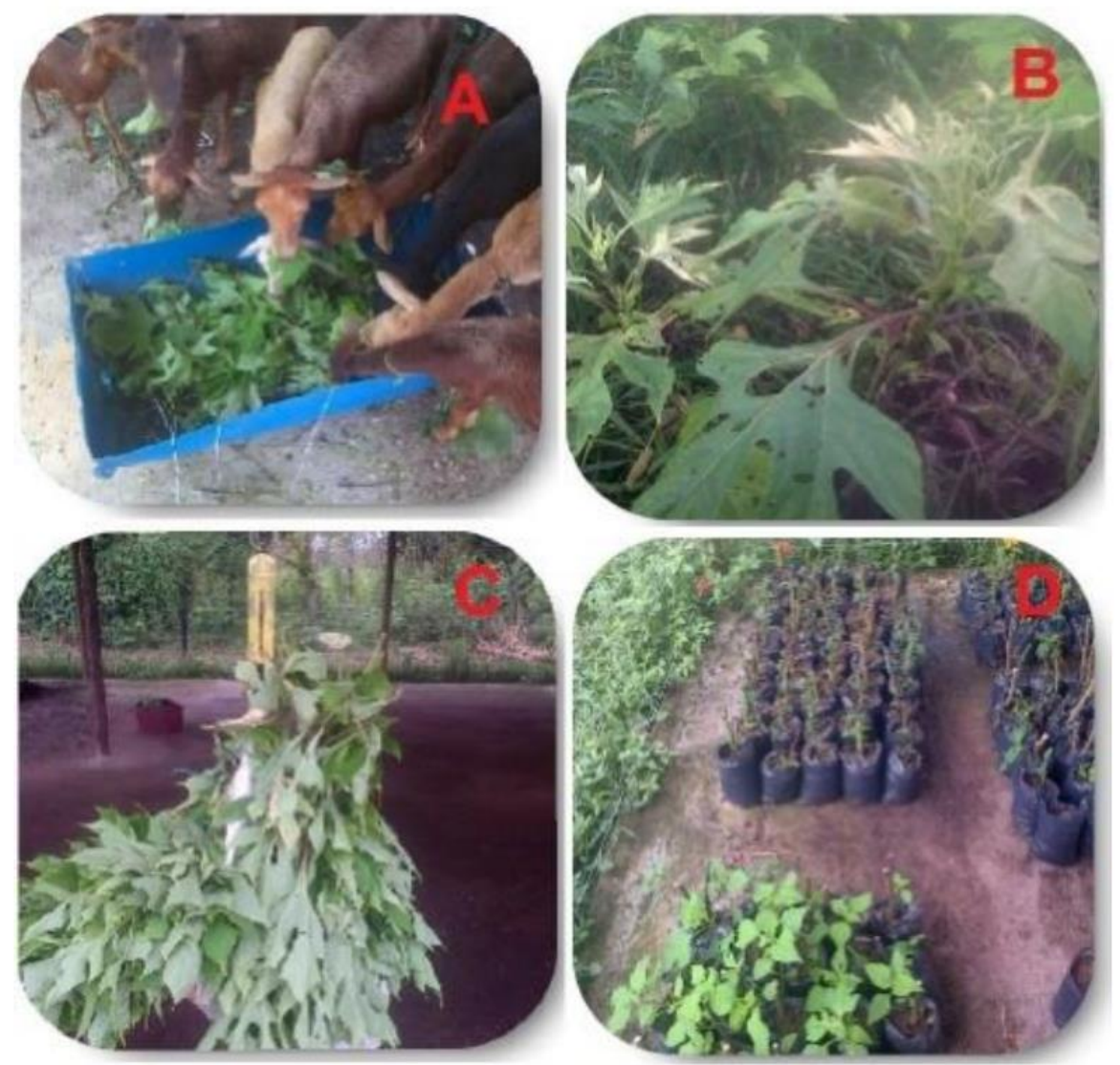

A: Consumo de Tithonia diversifolia por ovejas de pelo, B: Presencia de hojas masticadas por insectos y cambio de coloración, C: Pesaje de Tithonia diversifolia, D: Estacas de Tithonia diversifolia de diferentes edades Figura 6. Diferentes prácticas con Tithonia diversifolia

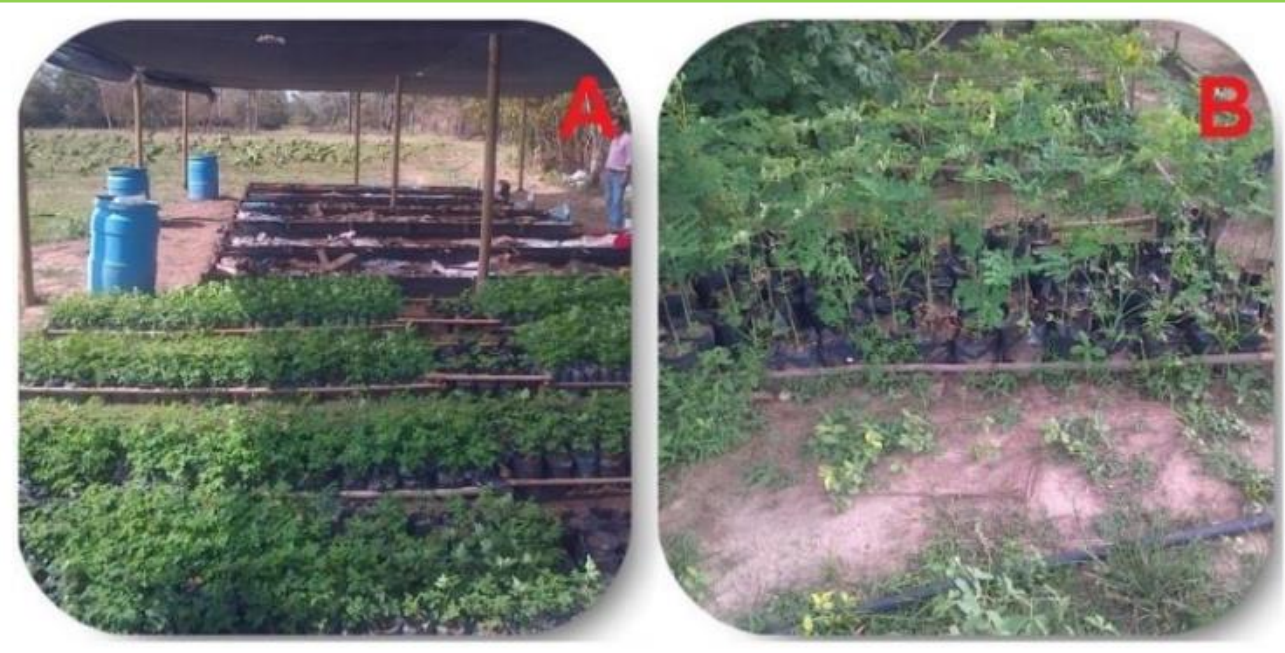

A: Crecimiento de plántulas en vivero, B: Plántulas que se dejaron con solo dos ramas Figura 7. Plántulas de Moringa oleifera en vivero. 


\section{BANCO DE PROTEÍNA CON Moringa oleifera}

El árbol de Moringa oleifera es objeto de estudio, puesto que la harina de su hoja se compara favorablemente con la leche en polvo en cuanto a sus componentes de proteína y de calcio, y tiene adicionalmente, un alto contenido de vitamina $A$. Además de su valor nutritivo, las hojas son ricas en antioxidantes, entre los cuales destacan los isotiocianatos, los cuales parecen presentar propiedades anticancerígenas, hipotensoras, hipoglucemiantes y antibióticas. La concentración de factores antinutritivos en las hojas, tales como inhibidores de proteasas, taninos, saponinas y lectinas, son insignificantes (Olson y Fahey, 2011).

\section{Siembra de Moringa oleifera}

Las semillas de moringa se sembraron en vivero durante un mes utilizando bolsas de polietileno con capacidad para $1 \mathrm{~kg}$, la cual se llenaba $3 / 4$ de tierra y $1 / 4$ de humus sólido. En total se sembraron 1121 plantas en un área de $1440 \mathrm{~m}^{2}$ distribuidos en dos lotes, se utilizaron 15.5 bultos $(40 \mathrm{~kg} \mathrm{c} / \mathrm{u})$ de humus sólido cuando se trasplantaron al sitio definitivo. En el primer lote, el cultivo se orientó en dirección oriente a occidente con una distancia de un metro entre surcos y plantas, mientras que en el segundo lote colocaron de norte a sur, y con distancias de un metro entre plantas y dos entre surcos, en el medio de los cuales se sembró yuca. Las plantas recibieron humus sólido en su siembra y en los periodos de cosecha, mediante el método de abonado que se puede apreciar en la Figura 9, la cantidad de humus utilizado fue un $\mathrm{kg}$ por planta (2 manotadas).

\section{Cosecha Moringa oleífera}

Se realizó un corte de nivelación a los 60 días de sembrada la Moringa oleífera, luego se hicieron tres cosechas cada 45 días, con el fin de evaluar la cantidad de rebrotes y de forraje verde para ser suministrados a los ovinos (Figura 8). La producción de materia fresca en el primer y segundo lote fue: 250 y $190 \mathrm{~g} / \mathrm{planta}$ respectivamente, se observó que la producción de biomasa de esta forrajera se disminuyó cuando se intercaló con yuca, además es de anotar que su producción 
fue baja debido al escaso crecimiento y alta mortalidad de las plantas. Estas evaluaciones se hicieron en un periodo de 195 días.

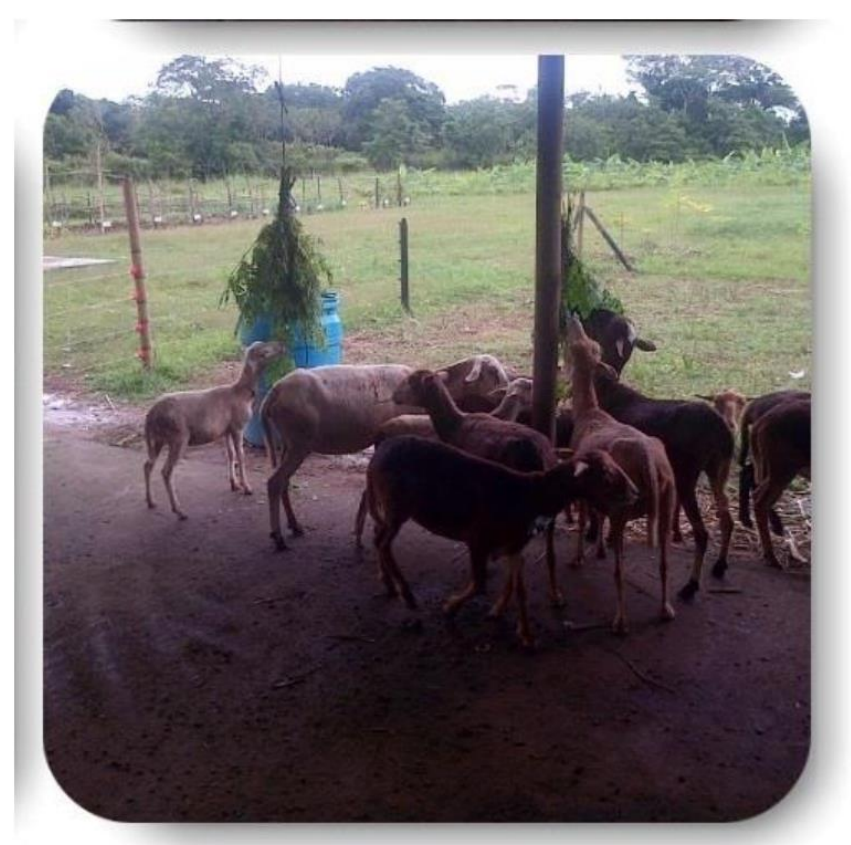

Figura 8. Consumo Moringa oleífera por ovejas de pelo en granja
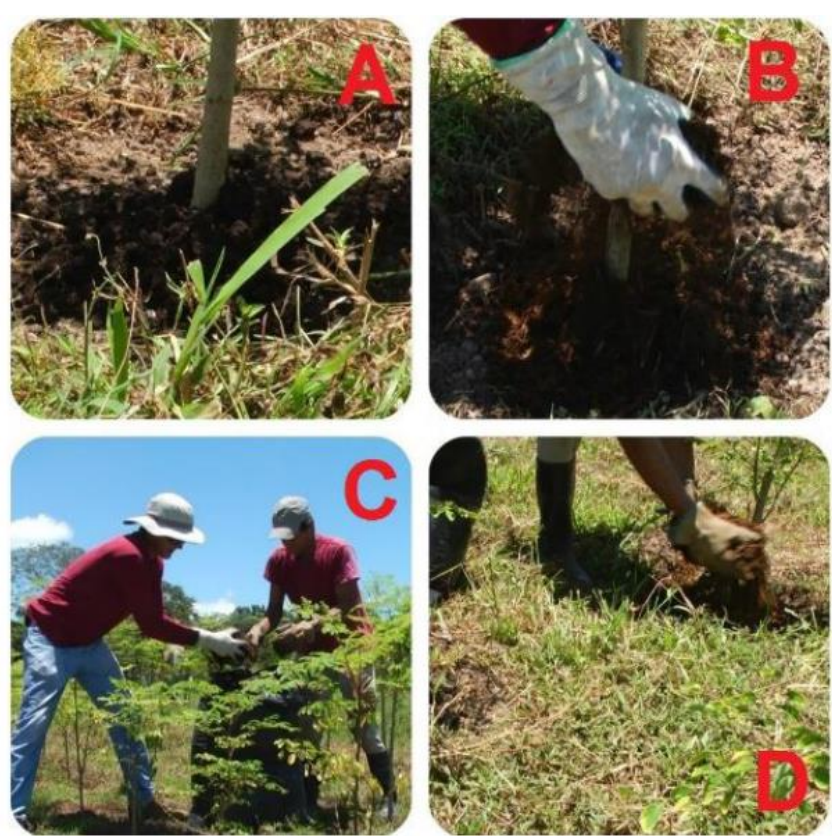

A: Aplicación de humus sólido (área previamente plateada) en el contorno del tallo de la planta, B: Protección de humus sólido (dos manotadas), C: Plantas de Moringa oleífera, D: Dos manotadas de cascarilla de arroz por planta Figura 9. Labores culturales Moringa oleífera 
Además, al comienzo, se observó en el primer lote sembrado con Moringa Oleífera intercalada con yuca, un mejor crecimiento en comparación con el segundo lote, pero al pasar el tiempo las plantas disminuyeron su crecimiento, posiblemente se debió a la competencia por luz solar, sin embargo en este lote se observaron plantas que estaban en floración y la presencia de vainas en crecimiento.

Se presentaron cambios en la coloración de las hojas (clorosis) de algunas plantas en los diferentes lotes, esta clorosis es el amarillamiento del tejido foliar causado por la falta de clorofila, sus causas posibles son el drenaje insuficiente, raíces averiadas o compactadas, alta acidez y deficiencias nutricionales del suelo, que por su bajo $\mathrm{pH}$ impide que los nutrientes sean biodisponibles para la planta. También se puede deducir que los nutrientes no puedan absorberse porque las raíces de las plantas están poco desarrolladas. En general, cuanto más tiempo dura la clorosis en la planta, más grave se torna, esta comienza con una leve decoloración (de verde claro a verde lima) del tejido internerval mientras que el color amarillo indica un problema más grave; en algunos casos, se torna clorótica una sola parte de la planta (Córdova, 2014).

\section{PASTO ELEFANTE, KING GRASS (Pennisetum purpureum var. Panamá común)}

El área de Pennisetum purpureum var. Panamá común tiene un total de $53 \mathrm{~m}$ de largo y 20 de ancho $\left(1060 \mathrm{~m}^{2}\right)$, el cultivo fue irrigado con 3 aspersores grandes y uno pequeño que cubren totalmente el área sembrada (52 surcos en total, después de 90 días de sembrado se empezó a cosechar el forraje y luego se realizaron dos cortes cada 45 días, para un total de 180 días de evaluación (Figura 10).

\section{Abono y cosecha del pasto de corte}

El abono se hizo con estiércol de bovino seco con cascarilla de arroz (Figura 11), y se aplicó entre los surcos orientados de norte a sur, el forraje se cosechó a una altura de 1.50-2.0 m, se observó que sus tallos eran jugosos y muy suculentos para los ovinos). 


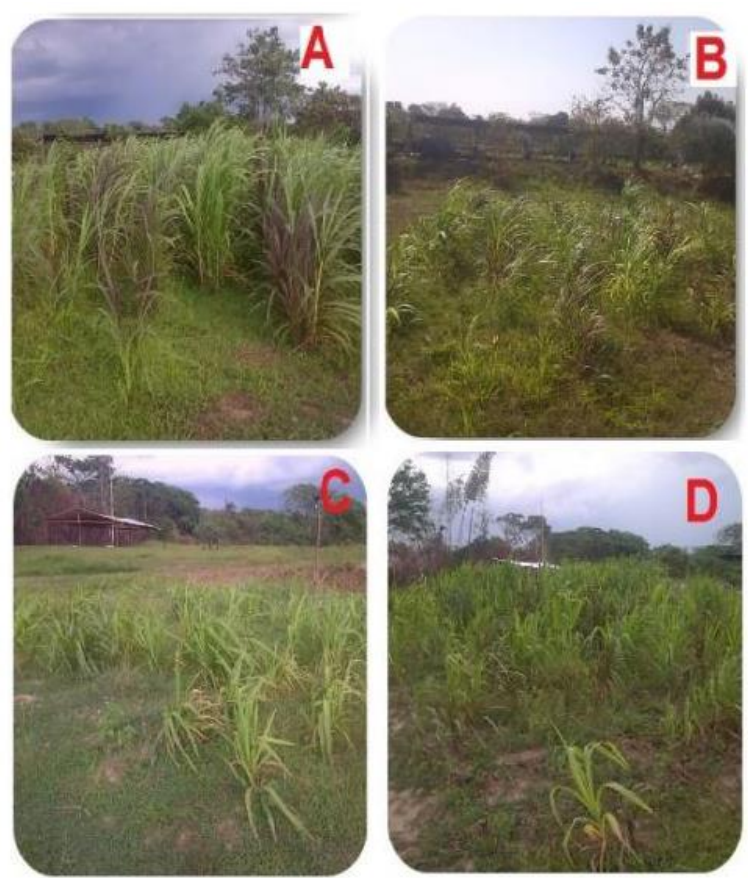

A: Surcos a cosechar, B: Plantas en crecimiento, C: Área pasto crecimiento atrasado, D: Pasto en crecimiento

Figura 10. Crecimiento y corte lote $P$. purpureum var. Panamá común

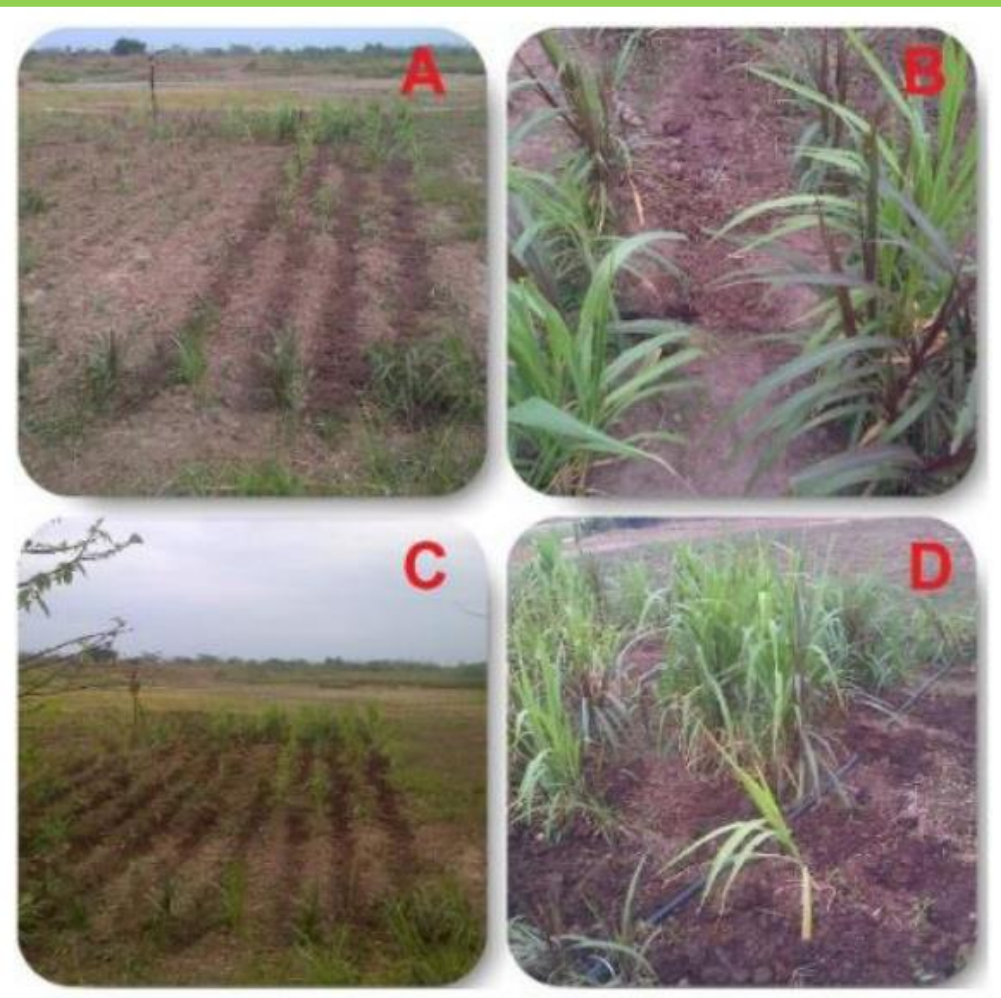

A: Estiércol seco entre surcos, B: Crecimiento plantas, C: Vista desde el vivero, D: Post-riego lote de pasto de corte (P. puerpureum)

Figura 11. Área de Pennisetum purpureum var. Panamá común 
La totalidad cosechada fue aproximadamente 4.5 toneladas, con una producción de $4 \mathrm{~kg} / \mathrm{m}^{2}$. La demanda de los animales se prevé superior a la oferta con el lote actual de pasto de corte, es por eso que se está adecuó otra área $\left(1.336 \mathrm{~m}^{2}\right)$ para ampliar el cultivo (Figura 12).

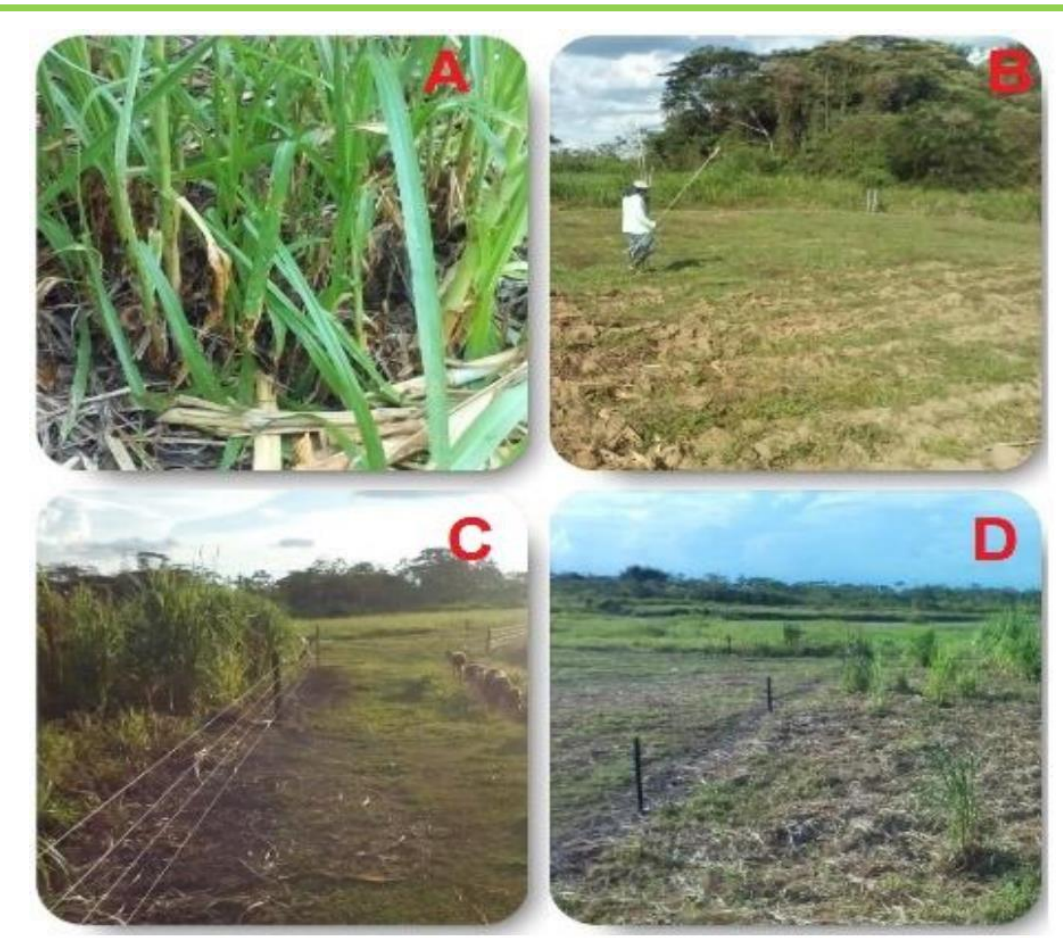

A: Retoño P. purpureum var. Panamá común luego de ser cortado a ras del suelo, B: Área destinada para ampliación del cultivo, C: Lote en cosecha, D: Nueva área de siembra del pasto de corte

Figura 12. Nuevas zonas y cortes

\section{LOMBRICULTIVO CON Eisenia foetida}

La finca cuenta con 6 camas de lombriz californiana (Eisenia foetida), cuyas medidas son $1.50 \mathrm{~m}$ de ancho por $5 \mathrm{~m}$ de largo y $40 \mathrm{~cm}$ de alto, distribuidas de oriente a occidente e identificadas con las letras, se alimentan con 6 bultos de residuos sólidos orgánicos de los sistemas de producción bovina (recogidos en el transcurso de la semana de fincas aledañas), se sembraron primero las camas B, $C$ y $D$ donde hay mayor cantidad de individuos por metro cuadrado. Las camas $E$, F y A se alimentan con 2 bultos cada una. Estas cantidades se aumentaron en razón al ofrecimiento de estiércol que provenía de las ovejas. El espesor del 
alimento ofrecido fue de $4-5 \mathrm{~cm}$, suministrando los residuos orgánicos cada ocho días, también se utilizaron los residuos caseros (Figura 13).

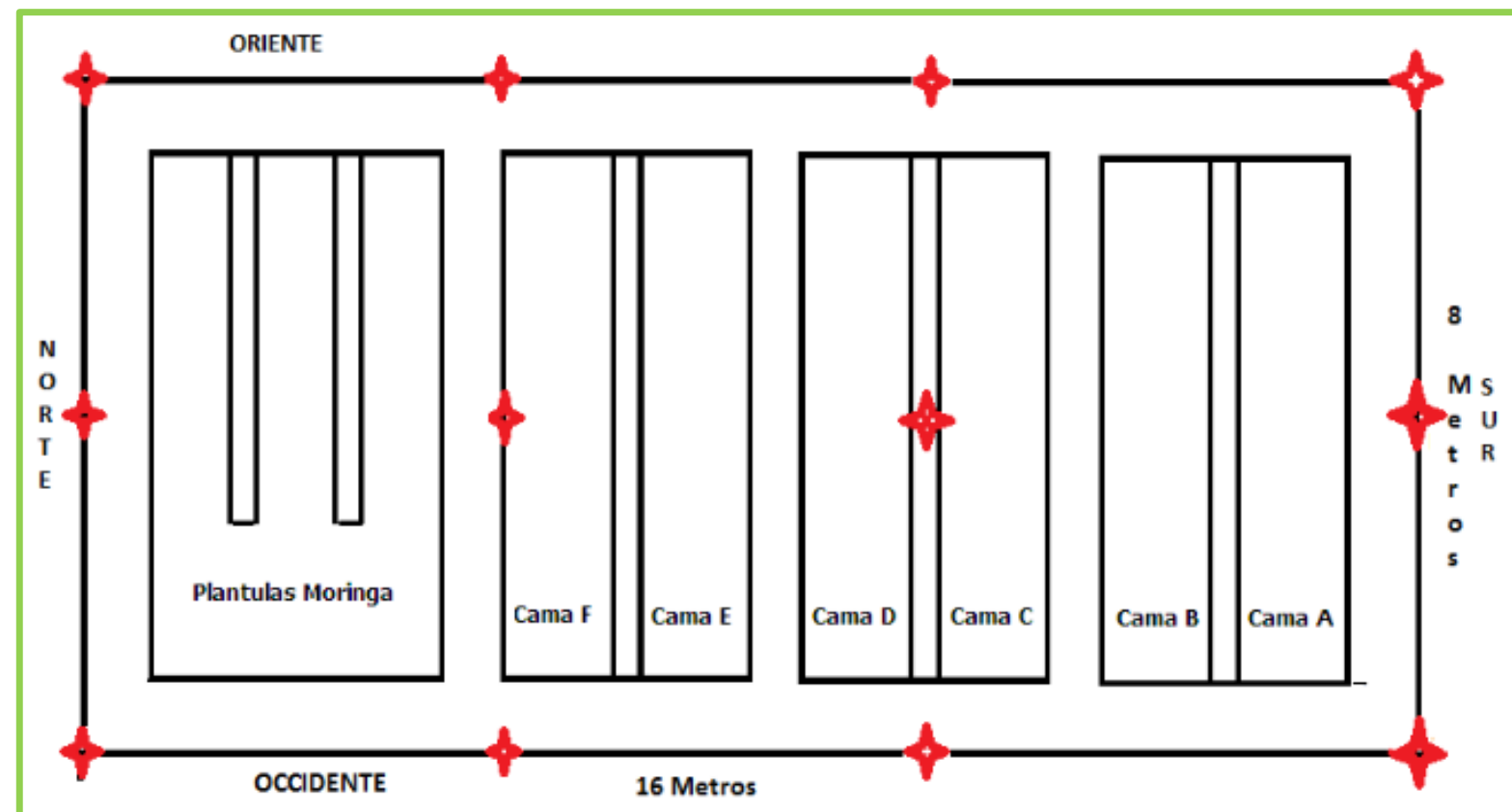

Figura 13. Mapa del área y disposición de las camas con Eisenia foetida

Diariamente del aprisco se recogen $20-23 \mathrm{~kg}$ de estiércol fresco, en la mañana cuando se limpia el aprisco, al principio cuando se estaban alimentando las camas con el estiércol de las ovejas, se observó un lento consumo por parte de las lombrices, la solución fue dejar el estiércol en el balde y llenarlo de agua hasta que se rebasara con el objetivo de humedecerlo para facilitar su consumo.

\section{Cosecha de Eisenia foetida}

Para cosechar una cama de lombriz se la deja sin alimento 5 días, luego se pone una malla para zaranda (agujeros de $5 \mathrm{~mm}$ ) y se coloca el estiércol esparcido para que ellas se suban al alimento (Figuras 14 y 15). Después de 3-6 días se recoge el material (lombrices y estiércol digerido) y se pasa a una nueva cama. Se mueve el material que hay entre los espacios que quedaron de las trampas esto con el fin de que no haya humedad y obligar al desplazamiento de las lombrices a los lugares húmedos (trampas). Las trampas se recogen a primera hora de la mañana (antes de que salga el sol fuerte), llevando el material de las camas que tienen de 
75 a $80 \%$ de humedad, a un lugar se baje ésta en un 35 a $40 \%$, aunque si el material se utiliza dentro de la granja no hay necesidad de secarlo.

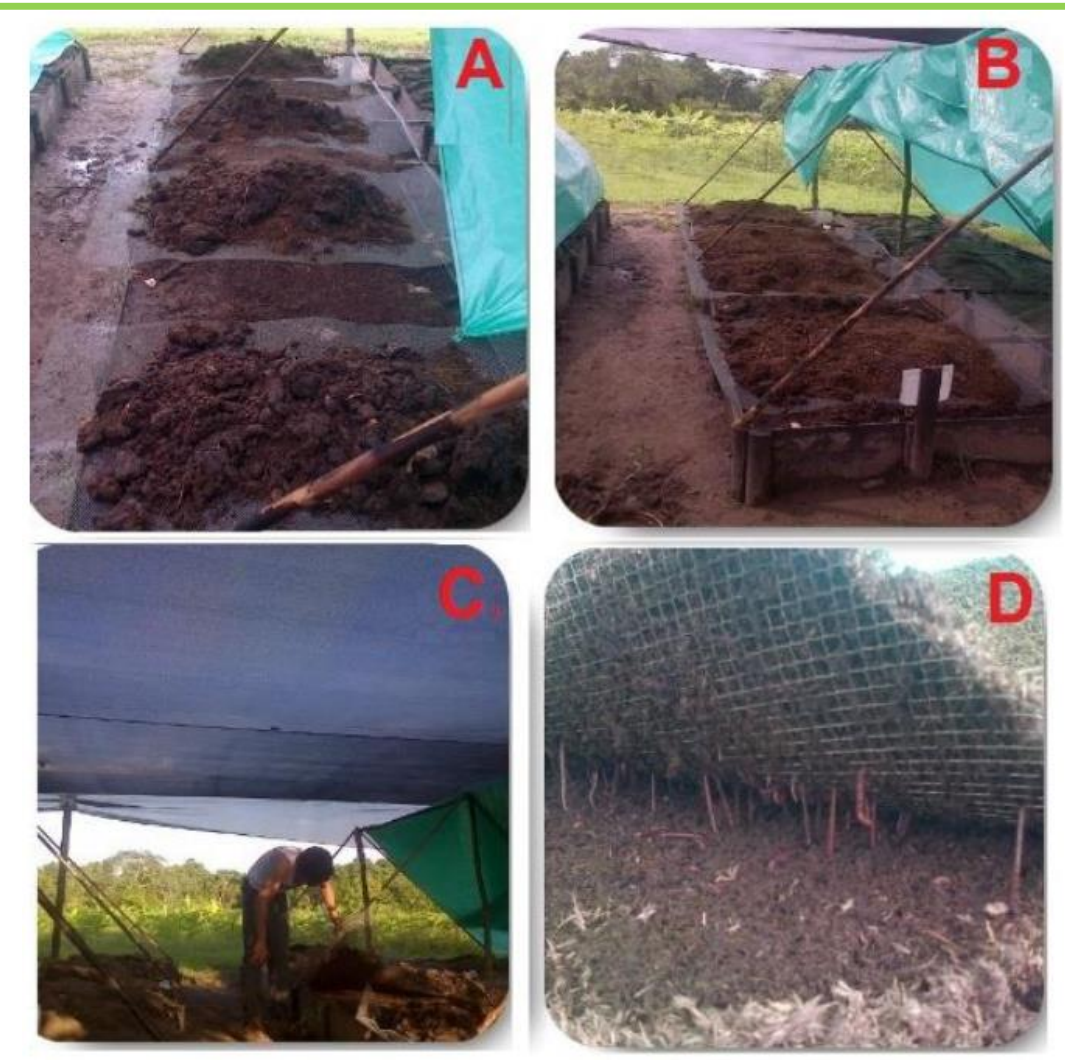

A: Alimento encima de la malla de captura,

B: Alimento digerido por E. foetida, C: Revisión captura E. foetida, D: Presencia de E. foetida en la trampa

Figura 14. Proceso de captura Eisenia foetida

Después de que se haya bajado la humedad al $35-40 \%$, el material se pasa por la zarande y se puede empacar; labor que no se ha ejecutado porque toda la producción se está usando para: huerta casera, cultivos como plátano, Moringa oleifera, Tithonia diversifolia, y yuca. Durante 180 días de evaluación se obtuvieron $18.250 \mathrm{~kg}$ de humus de lombriz, producto de 12 cosechas que se han hecho hasta el momento, dando un promedio por cosecha de cama de $254 \mathrm{~kg}$ de humus sólido, la cual se aumentó cuando las ovejas llegaron a la granja. 


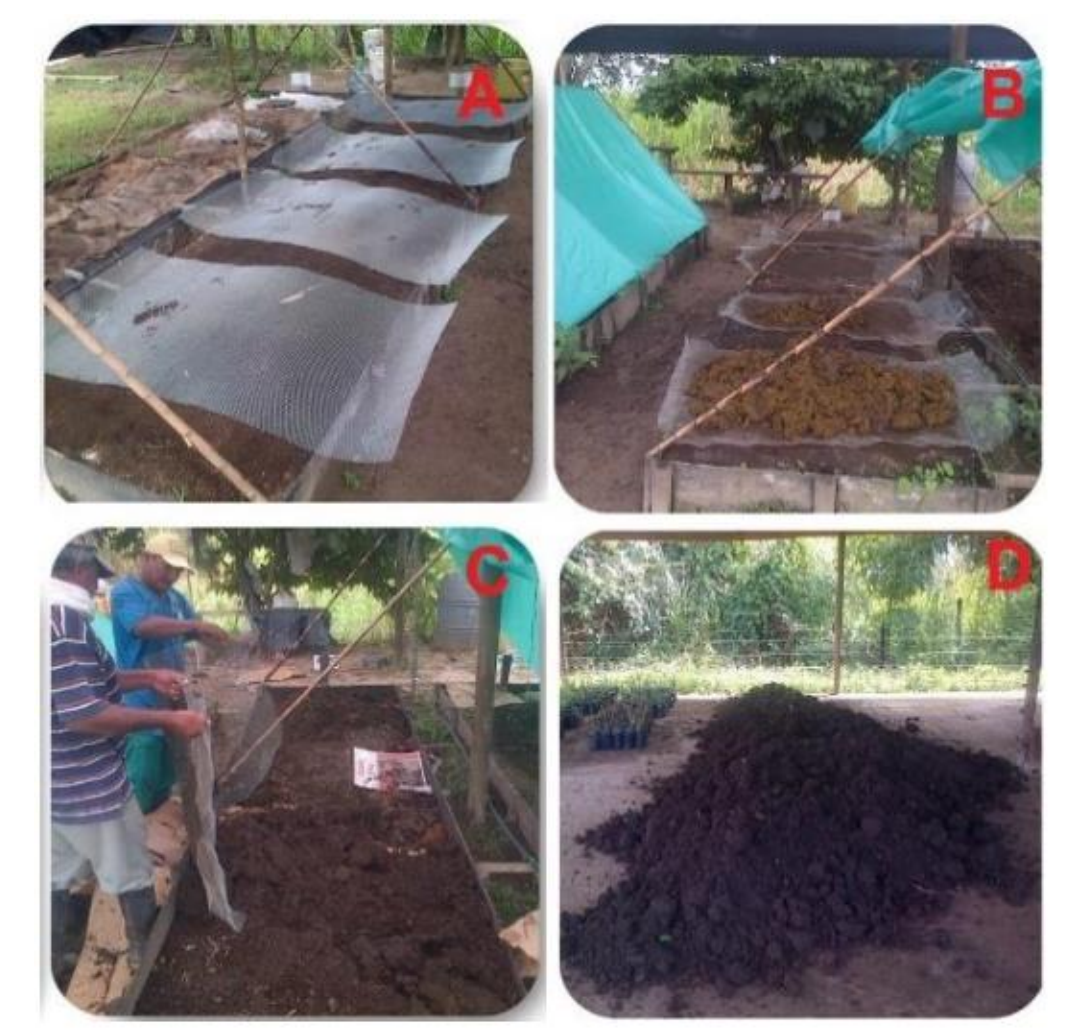

A: malla de captura, B: nueva cama para captura, C: siembra nueva cama lombriz, D: humus sólido cosechado para uso en granja Figura 15. Cosecha de camas

\section{Siembra de nueva cama con Eisenia foetida}

Luego de cosechar la cama, se procede a llenarla con cascarilla de arroz mezclada con estiércol (el mismo que se aplica al pasto de corte), también se adiciona hojas de papel reciclado, luego se humedece y se coloca la semilla de lombriz que fue capturada de otra cama próxima a cosechar, y se les deja alimento (estiércol humedecido), hasta la nueva cosecha, y así iniciar el mismo proceso con otra cama (Figura 16).

\section{Densidad de lombrices en la cama}

Para estimar la densidad de lombrices se tomó un tubo con $9 \mathrm{~cm}$ de diámetro y 28 $\mathrm{cm}$ de largo, introduciéndolo en diferentes sitios de la cama a cosechar para tomar varias sub-muestras (Figura 17B) y retirándolo posteriormente; se tomaron cinco submuestras, midiendo el espacio que no se llenó con lombrices (Figura 17A). De las submuestras tomadas se cuentan las lombrices que hay presentes sean 
grandes y pequeñas, estimando los volúmenes de éstas y número de lombrices atrapadas en el tubo (Tabla 1), luego se estima la densidad utilizando el resultado de lombrices contabilizadas con relación al volumen total de la cama $\left(3 \mathrm{~m}^{3}\right)$, generando una aproximación de la cantidad lombrices presentes en la cama.

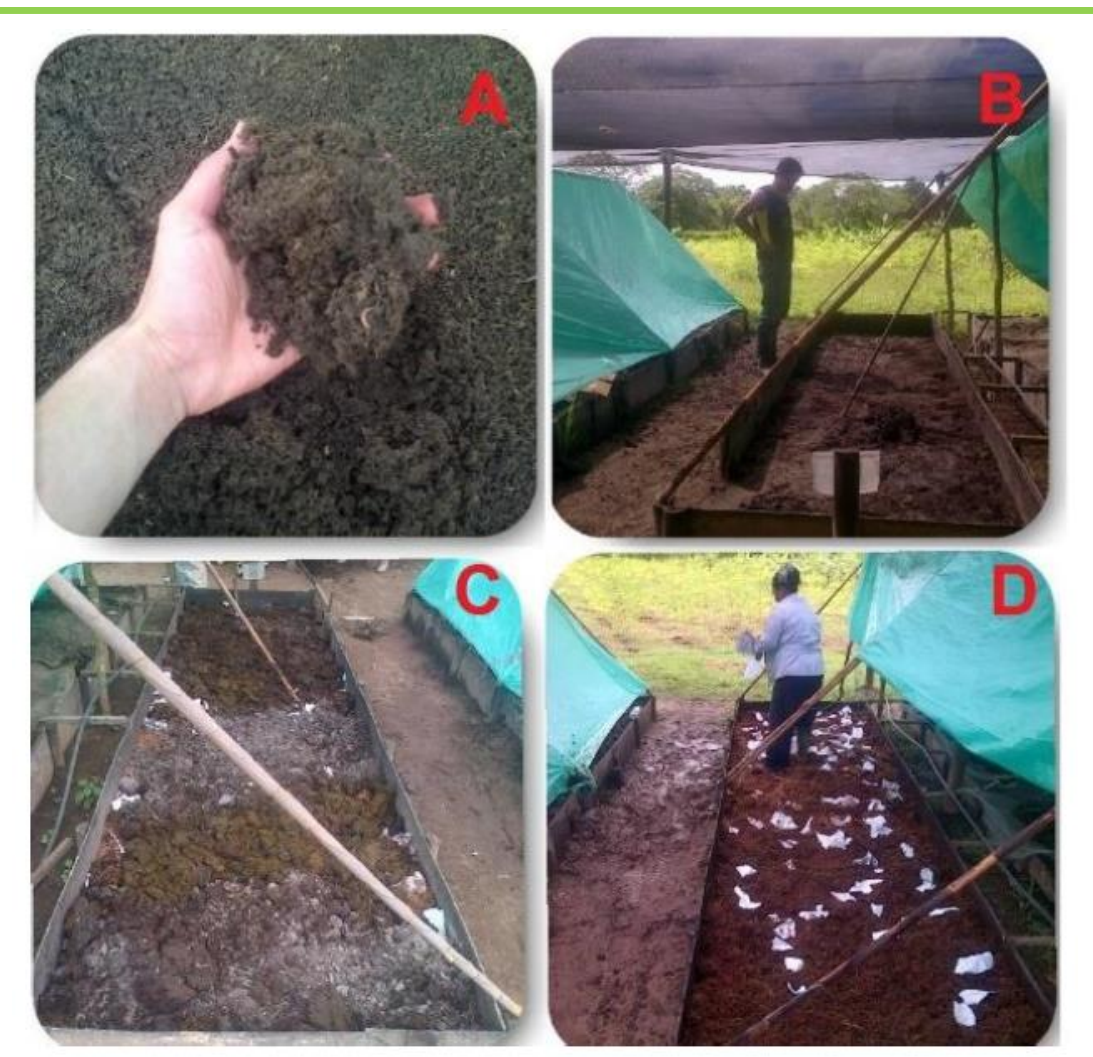

A: capa superficial cama E. foetida, B: cama desocupada y lista para nueva siembra, C: estiércol seco para seimbra de E. foetida,

D: Preparación de cama

Figura 16. Preparación cama para siembra Eisenia foetida

Tabla 1. Densidad de lombrices en la cama

\begin{tabular}{ccccc}
\hline Submuestra & $\begin{array}{c}\text { Largo (h) } \\
(\mathbf{c m})\end{array}$ & $\begin{array}{c}\text { Ancho } \\
(\mathbf{c m})\end{array}$ & $\begin{array}{c}\text { Volumen de } \\
\text { submuestra }\left(\mathbf{m}^{\mathbf{3}}\right)^{*}\end{array}$ & $\begin{array}{c}\text { Numero de } \\
\text { lombrices }\end{array}$ \\
\hline 1 & 16 & 9 & 0,001017 & 230 \\
2 & 12 & 9 & 0,000763 & 109 \\
3 & 14 & 9 & 0,000890 & 170 \\
4 & 13 & 9 & 0,000827 & 143 \\
5 & 14 & 9 & 0,000890 & 185 \\
& Total aforo & & $\mathbf{0 , 0 0 4 3 8 7}$ & $\mathbf{8 3 7}$ \\
& Total cama & & $\mathbf{3}$ & $\mathbf{5 7 2 . 3 7 3}$ \\
\hline
\end{tabular}

*Estimado mediante: $\mathrm{V}=\pi \times 4,5^{2} \times \mathrm{h}$ 


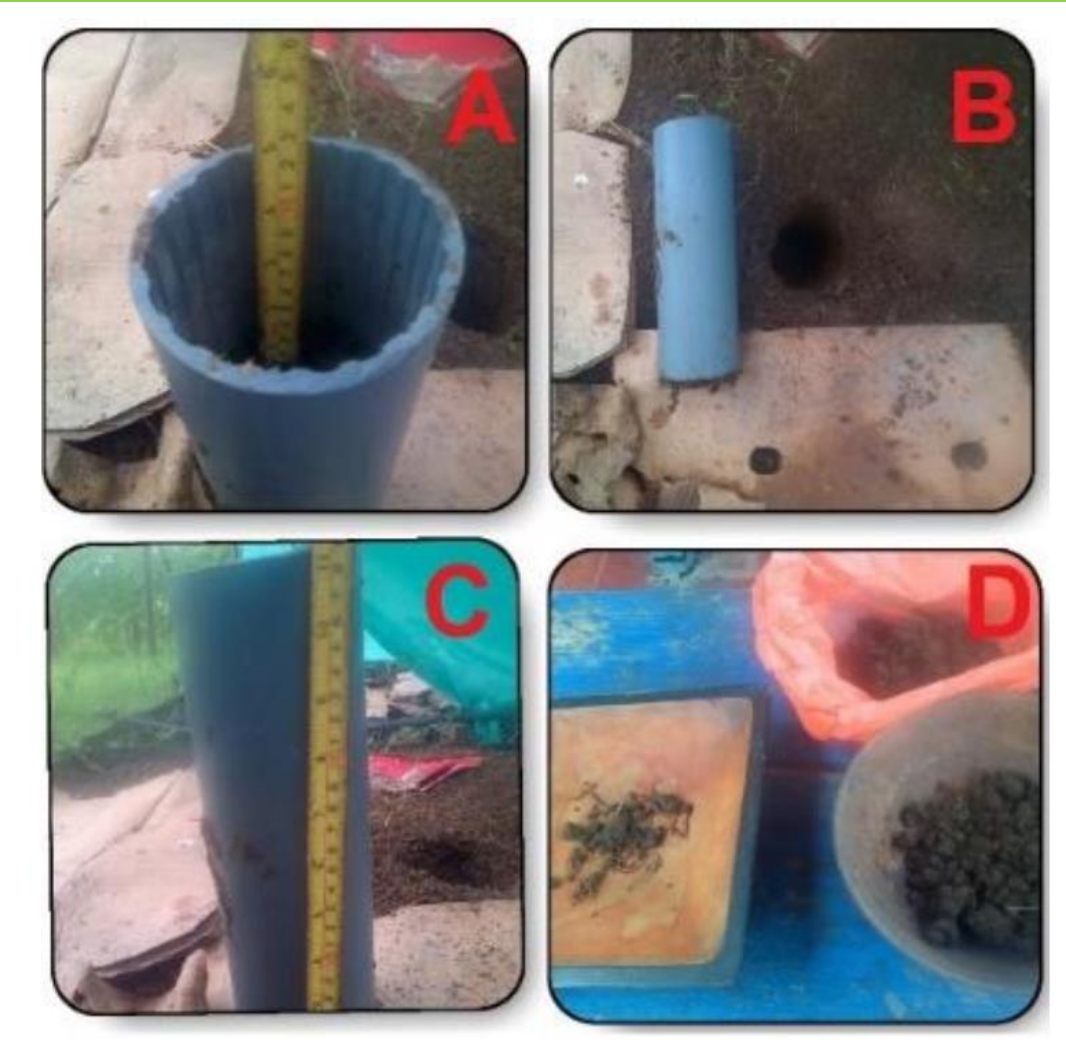

A: Medida de una de las submuetras, B: Muestra tomada de cama, C: Largo total del tubo, D: Separación de lombrices de las cinco submuestras

Figura 17. Aforo muestra cama D.

\section{ANÁLISIS}

Tithonia diversifolia (Botón de oro) demostró ser una especie que se adaptó muy bien en la granja, se comprobó que no tolera encharcamientos, y además no fue atacada por las hormigas del género Atta (hormiga arriera) mientras que Moringa oleifera fue afectada ocasionando mortalidad, se deduce que Tithonia diversifolia puede tener metabolitos secundarios con propiedades de controlar este insecto (Mahecha y Rosales, 2005). La altura de corte se hizo por encima de los $15 \mathrm{~cm}$ de altura, aprovechándose a su vez estacas con buen porte y vigorosidad para la siembra en bolsas de polietileno, no se reportaron muerte de plantas. Hernández, (2008) en un estudio de sobrevivencia de plantas en tres alturas de corte $(0,15 \mathrm{y}$ $30 \mathrm{~cm}$ ) demostró que en el segundo corte del tratamiento a nivel del suelo, hubo como promedio un $5.9 \%$ de mortalidad, lo cual constituye una tendencia negativa en cuanto a la persistencia de las planta. En el cultivo de Moringa oleífera en la granja, los mejores resultados fueron para el lote frente al vivero esto se ve 
reflejado por la cantidad de plantas establecidas y el área de producción. Teniendo en cuenta que la aparición de los signos de clorosis fue posterior a periodos de lluvia intensa y encharcamiento de varias plantas, posiblemente se debió a un drenaje insuficiente, se observó que la utilización de humus sólido ayudó a mejorar el drenaje haciendo más poroso el suelo y además protegiendo el humus con cascarilla de arroz aplicada en el contorno del tallo donde previamente se había plateado el área se conserva con más tiempo los nutrientes de este abono, (Basaure, 2004). Cada especie vegetal se halla asociada a una determinada combinación de factores climáticos que son los más favorables para su crecimiento, así como ciertos extremos de calor, frío o sequía más allá de los cuales las plantas no pueden sobrevivir (Falasca y Bernabé, 2008).

Para la cerca viva de Moringa oleifera se establecen a una distancia de un metro, controlando la producción de follaje mediante podas frecuentes (Olson y Fahey, 2011). Estas plántulas son susceptibles a la sequía, daño por viento y a la competencia con gramíneas, una vez establecidos, los árboles jóvenes en etapa de poste, son muy resistentes y capaces de sobrevivir a las sequías y competencia radicular. La yuca y Moringa oleifera se sembraron de manera intercalada entre surcos, la utilización del humus sólido fue fundamental para el establecimiento y mantenimiento de las mismas. Se evidenció que la aplicación de humus sólido, junto con el corte desde vivero de las ramas y el plateado en la base de la planta, mostró un mayor grosor del tallo que a su vez se traduce en mayor anclaje para vientos fuertes y aumento del rendimiento en biomasa por su capacidad de rebrote, además se observó menor presencia de clorosis en las hojas. Moringa oleifera rebrotó vigorosamente después de la poda, produciendo de cuatro a ocho renuevos por tocón, los arbustos cultivados por su fruta y para forraje frecuentemente se desmochan para restringir el desarrollo de la copa y promover el crecimiento de nuevas ramas (Toro et al., 2011). Ocasionalmente, las plántulas alcanzan 2.5 metros de alto 3 meses después de sembradas y entre 1.8 a $3.6 \mathrm{~m} 5$ meses después de sembradas (Olson y Fahey, 2011), en la granja se observaron unas pocas plantas con una altura superior a los $2.5 \mathrm{~m}$, las cuales a su vez se dejó seguir su crecimiento sin hacer poda con el fin de producir semilla. 
De la alimentación que reciben las lombrices, el 60\% lo emplean en su mantenimiento y reproducción y el $40 \%$ restante transforman en humus. Es decir que con $500 \mathrm{~kg}$ de alimento al año las lombrices sometidas a este proceso intensivo de cultivo producen 200 kilos de humus, con una población de 40000 lombrices por $\mathrm{m}^{2}$ (Esteve, 2008). Los resultados en la granja se consideran buenos en cuanto a producción de humus sólido que fueron de $254 \mathrm{~kg}$ por cama.

\section{CONCLUSIONES}

La implementación del banco de proteína con Tithonia diversifolia es viable en la granja, y sus cantidades cosechadas demuestran el potencial productivo y forrajero para la alimentación de ovinos. Mientras que Moringa oleifera no mostró una producción adecuada, es de anotar que ambas especies son consumidas con gusto y voracidad por los animales.

El lombricultivo ha mostrado ser un insumo clave en el desarrollo del proyecto, puesto que se usa el humus para fertilizar los cultivos, además la venta externa genera mejoramiento en la calidad de los suelos y un ingreso monetario adicional, por lo tanto, esta tecnología contribuye a solucionar dos de los problemas ambientales que se deben enfrentar en la actualidad: la acumulación de grandes concentraciones de residuos orgánicos en las fincas y la necesidad de materia orgánica en los suelos agrícolas.

El pasto de corte Pennisetum purpureum var. Panamá común demostró ser una gran ayuda en la alimentación de los animales, la proyección de la producción ovina en la granja, hace necesario la ampliación del cultivo, por su gran adaptación a las condiciones climatológicas y edafológicas.

\section{REFERENCIAS BIBLIOGRÁFICAS}

1. Basaure P. Manual de lombricultura Agroecología y Lombricultura. Chile. 2004. Recuperado 08 Marzo 2014. Disponible En: http://www.manualdelombricultura.com/foro/mensajes/7282.html

2. Córdova F. Dinámica del hierro en el sistema suelo-planta. Tesis de Grado Especialista en Suelo y Nutrición de Plantas. Instituto de Postgrado, Universidad Central de Ecuador. Quito, Ecuador. 65 p. 2014. 
3. Esteve JA. Manual práctico de técnicas de compostaje y lombricutura. 2008. Recuperado $08 \quad$ Marzo $2014 . \quad$ Disponible En: http://www.hortsecologics.net/documentacion/dosier curs o compost.pdf

4. Falasca S, Bernabé MA. Potenciales usos y delimitación del área de cultivo de Moringa oleífera en Argentina. Revista Virtual Redes, 2 (1): Art VII-2, 16 p. 2008. Disponible En: http://revistavirtual.redesma.org/vol3/pdf/investigacion/Moringa.pdf

5. González J, Hahn C, Narváez W. Características botánicas de Tithonia diversifolia (asterales: asteraceae) y su uso en la alimentación animal. Bol. Cient. Mus. Hist. Nat., 18 (2): 45-58. 2014.

6. Hernández A. Factores agronómicos que influyen en la producción de Tithonia diversifolia en la provincia de Matanzas. Trabajo de Curso. EEPF "Indio Hatuey" Sede Universitaria de Perico. Matanzas, Cuba. 23 p. 2008.

7. Inayat $A$, Gordon $O$. Influencia de las fases lunares (menguante y luna llena) sobre la propagación vegetativa del botón de oro Tithonia diversifolia para la formación de un banco de proteína: Tesis de Grado, Facultad de Ingeniería de Ciencias Agropecuarias, Sede el Prado, Quito, Ecuador. 2009.

8. Instituto de Hidrología, Meteorología y Estudios Ambientales (IDEAM). Atlas Climatológico de Colombia. 2014. Recuperado 12 Abril 2014. Disponible En: http://atlas.ideam.gov.co/visorAtlasClimatologico.html

9. Mahecha E, Rosales M. Valor nutricional del follaje de botón de oro (Tithonia diversifolia (Helmsl.) Gray, en la producción animal en el trópico. Livestock Research for Rural Development. 17 (9): Art. 100. 2005. Recuperado 13 Abril 2014. Disponible En: http://www.cipav.org.co//rrd//rrd17/9/mahe17100.htm

10. Mahecha L, Escobar JP, Suárez JF, Restrepo LF. Tithonia diversifolia (Hemsl.) Gray (botón de oro) como suplemento forrajero de vacas F1 (Holstein por Cebú). Livestock Research for Rural Development, 19 (2): Art. 16. 2007. Recuperado 12 Diciembre 2014. Disponible En: http://www.Irrd.org//rrd19/2/mahe19016.htm

11. Medina M, García D, González M, Cova LJ, Moratinos P. Variables morfoestructurales y de calidad de la biomasa de Tithonia diversifolia en la etapa inicial de crecimiento. Zootecnia Trop. 27 (2): 121-134. 2009.

12. Olson M, Faney J. Moringa oleifera: un árbol multiusos para las zonas tropicales secas. Revista Mexicana de Biodiversidad, 82 (4): 1071-1082. 2011.

13. Organización de las naciones unidas para la agricultura y la alimentación (FAO). Organic agriculture. Committee on Agriculture. 1999. Recuperado 09 Marzo 2014. Disponible En: www.fao.org/docrep/meeting/X0075E.htm

14. Organización de las naciones unidas para la agricultura y la alimentación (FAO). Agricultura orgánica, ambiente y seguridad alimentaria. El-Hage N, Hattman C (Ed), Roma. 280 p. 2003. Recuperado 10 Marzo 2014. Disponible En: http://www.fao.org/docrep/005/y4137s/y4137s00.htm

15. Pérez M, Rojas J. Hacia el desarrollo sostenible en Colombia. En: Documentos de política pública Piensa Colombia: los aportes de la academia. Tomo 1. Vol. 3. Universidad Nacional de Colombia. Bogotá. 2008.

16. Ramachandran C, Peter KV, Gopalakrishnan PK. Drumstick (Moringa oleifera): a multipurpose Indian vegetable. Economic Botany. 34 (3): 276-283. 1980.

17. Pérez A, Montejo I, Iglesias J, López O, Martín G, García D, Milián I, Hernández A. Tithonia diversifolia (Hemsl.) A. Gray. Pastos y Forrajes, 32 (1): 1-15. 2009.

18. Toro J, Carballo A, Rocha L. Valoración de las propiedades nutricionales de Moringa oleífera en el departamento de Bolívar. Revista de Ciencias, 15: 22-30. 2011. 